\title{
Identifikasi Karakteristik Hewan Kurban Di Masjid Kompleks Perumahan Wilayah Kota Bogor
}

\author{
Identify Characteristics of Qurban Animals at Residential Area Mosque of Bogor City \\ Komariah*, S. Rahayu, V. A. Mendrofa, \& S. Priyanto \\ Departemen Ilmu Produksi dan Teknologi Peternakan, Fakultas Peternakan, Institut Pertanian Bogor \\ Jl. Agatis, Kampus IPB Darmaga Bogor 16680, Indonesia \\ *Corresponding author: komariah_purjati@yahoo.com \\ (Received 23-08-2021; Revised 01-10-2021; Accepted 13-10-2021)
}

\begin{abstract}
Eid al-Adha is commemorate by moslems every $10^{\text {th }}$ Dzulhijjah with by doing the Eid al-Adha prayer then followed by qurban worship for those who are capable. The aim of this study is to identify characteristics qurban animals at mosque in residential area, Bogor city. The number $f$ qurban animals was 314 heads consisting of 95 heads of cattle, 204 heads of sheep and 15 heads of goats. The research method used was by observing the qurban animals at the research site. The data obtained were then analyzed descriptively. The results showed that the majority of the qurban animals were bali cattle aged $\geq 4$ years $(33.3 \%)$ with a BCS of 4, thin tail sheep aged 2.5-3.0 years (28.9\%) with a BCS of 3, Jawarandu goats aged 2.5-3.0 years $(37.8 \%)$ with a BCS of 4 and the identified qurban animals have met sharia requirements.
\end{abstract}

Keywords: catlle, goat, identify, qurban, sheep

\begin{abstract}
ABSTRAK
Hari Raya Idul Adha diperingati seluruh umat muslim setiap tanggal 10 Dzulhijjah dengan menjalankan shalat Idul Adha dilanjutkan ibadah kurban bagi yang mampu. Penelitian ini bertujuan mengidentifikasi karakteristik hewan kurban di kompleks perumahan wilayah kota Bogor. Jumlah hewan kurban sebanyak 314 ekor meliputi sapi 95 ekor, domba 204 ekor dan kambing 15 ekor. Metode penelitian yang dengan melakukan observasi langsung hewan kurban. Data yang diperoleh kemudian dianalisis secara deskriptif. Hasil penelitian menunjukan hewan kurban yang dipotong mayoritas sapi bali dengan umur $\geq 4$ tahun sebesar 33.3\% dengan BCS 4, domba ekor tipis umur 2.5-3.0 tahun sebesar 28.9\% dengan BCS 3, kambing Jawarandu dengan umur 2.5-3.0 tahun sebesar 37.8\% dengan BCS 4 dan hewan kurban yang digunakan sesuai syariah.
\end{abstract}

Kata kunci: domba, identifikasi, kambing, kurban, sapi

\section{PENDAHULUAN}

Kota Bogor merupakan salah satu kota dengan jumlah penduduk muslim yang terbanyak. Menurut BPS Kota Bogor 2019 pada tahun 2017 tercatat sebanyak 1.064.687 orang. Hari Raya Idul Adha diperingati seluruh umat muslim di dunia maupun di Indonesia setiap tanggal 10 Dzulhijjah dengan menjalankan shalat Idul Adha dilanjutkan ibadah kurban bagi yang mampu (Amanda et al. 2017). Ibadah kurban adalah menyembelih hewan kurban dan mensyukuri nikmat yang telah Allah SWT berikan (Noviati 2017). Ibadah kurban dilakukan dengan cara menyembelih kambing, domba, atau sapi yang kemudian dagingnya dibagikan kepada masyarakat yang membutuhkan dan dilaksanakan sesuai dengan syariah (Khamzah 2016). Ibadah kurban bersifat sunnah muakad yaitu ibadah sunnah yang sangat dianjurkan untuk dilaksanakan (Kementerian Agama 2010).

Konsumen hewan kurban cenderung memilih ternak yang sehat dengan harga terjangkau serta memenuhi kriteria hewan kurban (Komariah et al. 2015). Hewan kurban sebaiknya hewan yang paling baik, gemuk, sehat, tidak cacat seperti buta dan pincang, serta memenuhi syarat umur yaitu satu tahun untuk kambing dan domba, dua tahun untuk ternak sapi (Kementerian Agama 2010). Pemilihan hewan kurban yang dilakukan masyarakat umumnya masih 
kurang tepat. Hal ini dikarenakan masyarakat masih kurang mengerti mengenai syarat hewan kurban yang dianjurkan dalam agama Islam. Masyarkat awam pada umumnya membeli hewan kurban didasarkan pada rasa suka terhadap hewan kurban tersebut dan memilih harga yang terjangkau. Menurut Utsaimin (2002) bahwa syarat hewan kurban yakni jenis hewannya harus binatang ternak (unta, sapi, kambing, domba), usia hewan tersebut telah memenuhi kriteria yang telah ditetapkan oleh syariat, hewan kurban tersebut tidak memilki cacat yang bisa menghalangi keabsahannya, hewan yang hendak digunakan untuk berkurban milik sendiri atau milik orang lain tetapi telah sah secara syariat atau telah mendapatkan izin dari pemilik, hewan kurban tersebut tidak berkaitan dengan hak orang lain, dan penyembelihan hewan kurban dilakukan pada waktu yang telah ditentukan secara syar'i.

Perumahan di Kota Bogor didominasi oleh masyarakat kalangan menengah keatas. Masyarakat perumahan umumnya memiliki tingkat pendidikan yang lebih tinggi dibandingkan dengan masyarakat awam pada umumnya. Masyarakat perumahan biasanya akan lebih paham dengan urusan keagamaan. Hal ini menyebabkan hewan kurban yang ada di perumahan seharusnya memiliki karakteristik yang sesuai syarat hewan kurban yang diwajibkan oleh agama Islam, sehingga penelitian ini bertujuan mengidentifikasi dan mengetahui karakteristik hewan kurban di Masjid kompleks perumahan di wilayah Kota Bogor yang tidak sesuai syariah.

\section{MATERI DAN METODE}

\section{Materi}

Alat yang digunakan dalam penelitian ini adalah kamera, alat tulis, dan wear pack. Bahan atau materi yang digunakan adalah borang kuesioner dan hewan kurban sebanyak 314 ekor meliputi sapi 95 ekor, domba 204 ekor dan kambing 15 ekor.

\section{Metode}

\section{Penentuan Lokasi}

Lokasi ditentukan dengan cara purpossive sampling (Palinkas et al. 2015). Purpossive sampling dengan menentukan lokasi pemotongan hewan kurban secara sengaja di masjid dalam kawasan perumahan Kota Bogor. Masjid yang menjadi lokasi penelitian memiliki kriteria yakni menyembelih hewan kurban di atas 20 ekor per masjid. Berikut prosedur pengumpulan data di lokasi sesuai kriteria di atas.

\section{Pengumpulan Data}

Data yang dikumpulkan adalah data primer dan sekunder. Data primer diperoleh dengan cara melakukan pengamatan dan perabaan hewan kurban. Indentifikasi hewan kurban yang dilakukan yakni bangsa ternak (postur tubuh, warna bulu dan tanduk), umur ternak berdasarkan gigi (Sosroamidjojo dan Soeradji 1982) (Tabel 1), dan BCS dengan pengamatan dan perabaan tubuh (Sukandar et al. 2008) (Tabel 2).
Tabel 1. Pendugaan umur berdasarkan perubahan gigi seri*

\begin{tabular}{|c|c|c|c|c|}
\hline \multirow{2}{*}{$\begin{array}{c}\text { Gambar } \\
\text { gigi }\end{array}$} & \multirow{2}{*}{$\begin{array}{l}\text { Klasifikasi } \\
\text { gigi }\end{array}$} & \multicolumn{3}{|c|}{ Perkiraan umur ternak } \\
\hline & & Sapi & Domba & Kambing \\
\hline & & $\ldots \ldots$ & - tahun- & $-\ldots-\ldots$ \\
\hline & $\mathrm{I}_{0}$ & $<1.5$ & $<1.0$ & $<1.0$ \\
\hline & $\mathrm{I}_{1}$ & $2.0-2.5$ & $1.0-1.5$ & $1.0-1.5$ \\
\hline & $\mathrm{I}_{2}$ & $3.0-3.5$ & $1.5-2.0$ & $1.5-2.0$ \\
\hline & $\mathrm{I}_{3}$ & $3.5-4.0$ & $2.5-3.0$ & $2.5-3.0$ \\
\hline & $\mathrm{I}_{4}$ & $>4.0$ & $3.5-4.0$ & $3.5-4.0$ \\
\hline
\end{tabular}

*Sosroamidjojo dan Soeradji (1982)

Tabel 2. Deskripsi penilaian Body Condition Score (BCS)*

\begin{tabular}{|c|c|c|}
\hline Skor & Kategori & Deskripsi \\
\hline \multirow[t]{2}{*}{1} & Sangat kurus & $\S$ Tidak ada lemak di sekitar ekor \\
\hline & & $\begin{array}{l}\S \text { Tulang pinggul, pangkal ekor, tulang } \\
\text { rusuk secara visual terlihat jelas }\end{array}$ \\
\hline \multirow[t]{2}{*}{2} & Kurus & $\begin{array}{l}\S \text { Tulang rusuk dapat diidentifikasi bila } \\
\text { disentuh mulai sedikit tidak jelas }\end{array}$ \\
\hline & & $\begin{array}{l}\S \text { Pangkal ekor, tulang pinggul, dan } \\
\text { panggul mulai tertutupi lemak }\end{array}$ \\
\hline \multirow[t]{2}{*}{3} & Sedang & $\begin{array}{l}\S \text { Tulang rusuk dapat dirasakan dengan } \\
\text { tekanan tangan }\end{array}$ \\
\hline & & $\begin{array}{l}\S \text { Pangkal ekor tertutupi lemak dan } \\
\text { dapat dengan mudah dirasakan }\end{array}$ \\
\hline \multirow[t]{2}{*}{4} & Gemuk & $\begin{array}{l}\S \text { Lemak penutup di sekitar pangkal } \\
\text { ekor jelas, sedikit membulat, lembek } \\
\text { bila disentuh }\end{array}$ \\
\hline & & $\begin{array}{l}\S \text { Lipatan lemak mulai berkembang di } \\
\text { atas tulang rusuk dan paha ternak }\end{array}$ \\
\hline \multirow[t]{3}{*}{5} & Sangat gemuk & $\begin{array}{l}\S \text { Struktur tulang tidak lagi nyata dan } \\
\text { ternak menunjukan penampilan yang } \\
\text { sintal dan membulat }\end{array}$ \\
\hline & & $\begin{array}{l}\S \text { Tulang pinggul, pangkal ekor, tulang } \\
\text { rusuk, dan paha dipenuhi dengan lipa- } \\
\text { tan lemak }\end{array}$ \\
\hline & & $\begin{array}{l}\S \text { Mobilitas ternak lemah yang diaki- } \\
\text { batkan oleh lemak yang dibawanya }\end{array}$ \\
\hline
\end{tabular}

*Sukandar et al. (2008) 


\section{Analisis Data}

Penelitian ini menggunakan analisis deskriptif kuantitatif. Data didapatkan dari kuesioner yang berisi tabel penilaian mengenai jenis, umur, bangsa, dan BCS. Data-data tersebut kemudian dimasukan ke dalam software microsoft excel untuk selanjutnya dianalisis secara deskriptif.

\section{HASIL DAN PEMBAHASAN}

\section{Keadaan Umum Penelitian}

Lokasi penelitian terletak di lima masjid dalam tiga kompleks perumahan yakni Masjid Raya, Masjid Al Istiqomah, dan Masjid Jami Darussalam di Perumahan Yasmin Sektor II, Masjid Baitussalam di Perumahan Bogor Raya Permai, dan Masjid Al Hidayah Perumahan Bukit Cimanggu City. Hewan kurban yang akan dipotong sebelumnya diikat di patok besi atau kayu yang beratap tenda di lahan kosong sekitar masjid. Berikut kondisi hewan kurban sebelum pemotongan di semua lokasi (Gambar 1).

\section{Profil Hewan Kurban Sapi}

Sebaran bangsa sapi di lokasi penelitian meliputi bangsa sapi limosin, bangsa sapi simmental, bangsa sapi PO, bangsa sapi bali, bangsa sapi pesisir, bangsa sapi angus, dan bangsa sapi madura (Gambar 2). Jumlah sapi yang menjadi hewan kurban di lima lokasi penelitian berjumlah 95 ekor. Persentase tertinggi bangsa sapi di lokasi penelitian yakni bangsa sapi bali yaitu sebesar 32\% dari total sapi yang menjadi hewan kurban. Terdapat satu sapi pesisir yang hanya ada di lokasi Masjid Baitussalam.

Masyarakat perumahan di lokasi penelitian umumnya menyukai sapi bali dikarenakan jumlahnya yang cukup banyak di pasaran. Handiwirawan dan Subandriyo (2004) mengatakan bahwa sapi bali merupakan sapi asli Indonesia yang cukup penting karena terdapat dalam jumlah cukup banyak dengan wilayah penyebarannya yang luas di Indonesia. Selain itu, harga sapi bali juga terjangkau dibandingkan dengan bangsa sapi lain dan memiliki kondisi tubuh yang gagah. Menurut Komariah et al. (2015) umumnya konsumen akan memilih ternak yang sehat dengan harga terjangkau serta memenuhi kriteria hewan kurban. Sapi yang akan dijadikan hewan kurban harus memiliki umur sesuai syarat hewan kurban. Menurut Utsaimin (2002) bahawa untuk ternak sapi yang dijadikan hewan kurban telah genap dua tahun. Hasil tabulasi jumlah dan persentase umur sapi yang berada di lima lokasi penelitian disajikan pada Gambar 3.

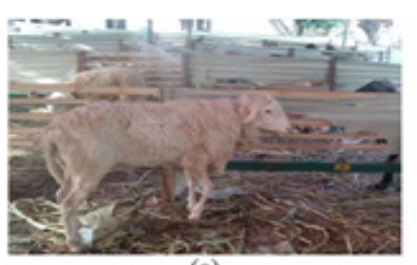

(a)

Masjid Baitussalam Bogor Raya Permai

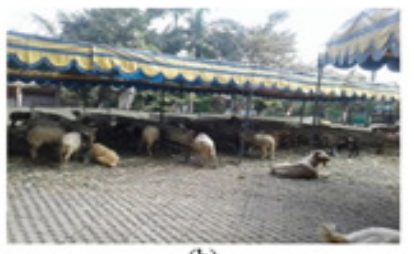
(b) Masjid Raya Yasmin

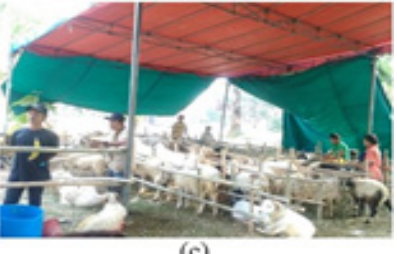

(c)

Masjid Al-Hidayah Bukit Cimanggu City

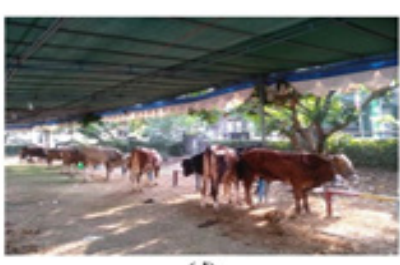

(d)

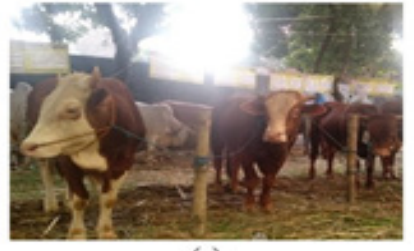

(e)

Masjid Al-Istiqomah Yasmin

Gambar 1. Kondisi hewan kurban sebelum pemotongan di semua lokasi

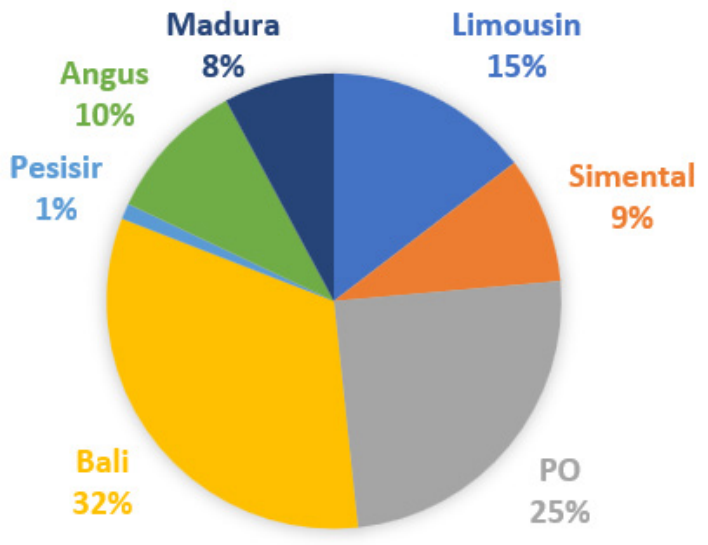

Gambar 2. Persentase sapi berdasarkan bangsa 


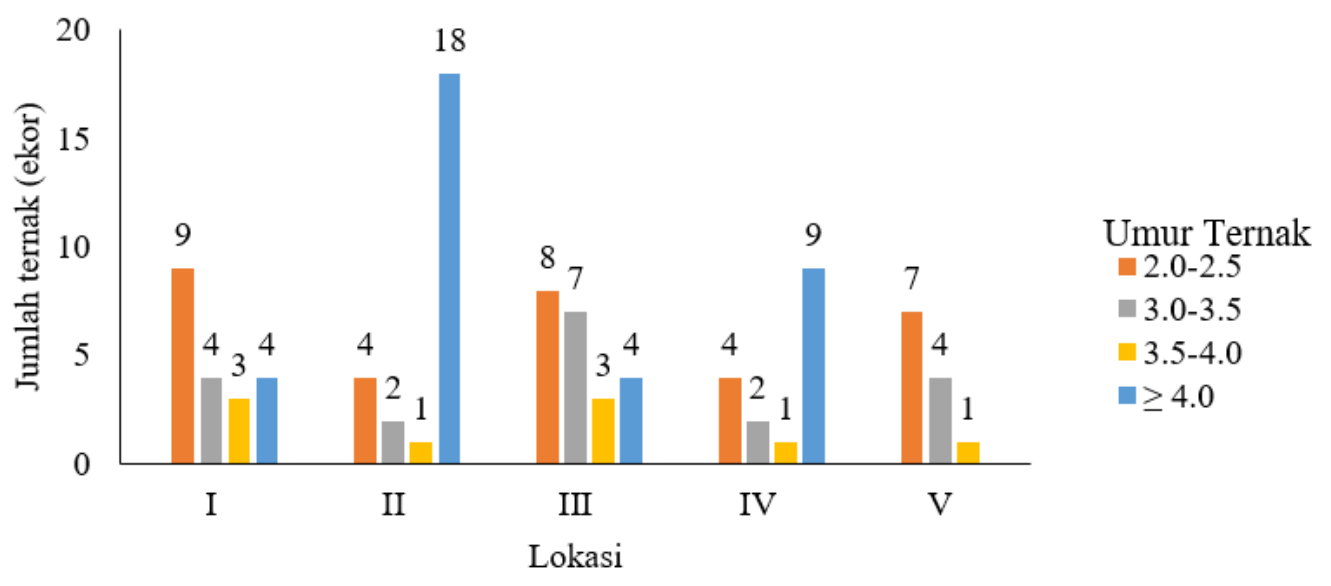

Gambar 3. Jumlah hewan kurban sapi berdasarkan umur

Semua sapi yang dijadikan hewan kurban di lima lokasi penelitian memiliki umur yang sesuai syarat hewan kurban yakni berumur lebih dari dua tahun. Rataan umur sapi didominasi sapi dengan umur 2.0-2.5 tahun yaitu sebesar $36.2 \%$. Masyarakat perumahan yang ada di lokasi penelitian sudah mengetahui mengenai syarat umur sapi yang dijadikan sebagai hewan kurban. Hal ini ditandai dengan tidak adanya sapi yang yang berumur dibawah dua tahun. Umumnya sebelum Hari Raya Idul Adha, dilakukan sosialisasi oleh Dewan Keluarga Masjid (DKM) mengenai pentingnya berkurban dan syarat ataupun ketentuan mengenai hewan yang layak dijadikan hewan kurban.

Persentase rataan BCS (Gambar 4) sapi yang dijadikan hewan kurban didominasi oleh skor BCS 4 yakni sebesar $44.1 \%$. Artinya rata-rata ternak sapi yang dijadikan hewan kurban di lima lokasi penelitian memiliki postur tubuh yang gemuk. BCS memiliki hubungan erat dengan status cadangan energi tubuh ternak dimana cadangan energi erat hubungannya dengan gizi yang dikonsumsi (Anisa et al. 2017). Masyarakat perumahan di lima lokasi penelitian menyukai ternak sapi yang gemuk dan sehat. Hal ini dikarenakan masyarakat di perumahan sudah memiliki tingkat pendidikan dan tingkat ekonomi yang tinggi sehingga paham mengenai syarat dan anjuran ternak yang akan dijadikan hewan kurban.

\section{Profil Hewan Kurban Domba}

Domba merupakan ternak ruminansia kecil yang memiliki kemampuan berdaptasi di daerah gersang. Jumlah dan persentase domba berdasarkan bangsa disajikan pada Gambar 5. Persentase bangsa domba tertinggi di lokasi penelitian adalah bangsa domba ekor tipis sebesar $85 \%$. Domba ekor tipis mendominasi dibandingkan dengan domba bangsa lainnya. Populasi domba ekor tipis yang ada di Indonesia $80 \%$ berada di Jawa Barat dan Jawa Tengah. Domba wonosobo hanya terdapat di lokasi II sebanyak dua ekor. Masyarakat perumahan di lokasi penelitian menyukai domba ekor tipis. Hal ini dikarenakan domba ekor tipis memiliki postur tubuh yang kokoh dan memiliki tanduk yang gagah. Selain itu domba ekor tipis harganya lebih murah dibandingkan dengan domba garut. Masyarakat perumahan di lokasi penelitian memilih ternak domba yang memiliki tanduk. Hal ini dibuktikan dengan persentase domba ekor tipis dan domba garut yang mendominasi.

Umur domba merupakan salah satu indikator kelayakan domba untuk dijadikan hewan kurban. Hewan kurban harus memenuhi syarat umur yaitu satu tahun untuk domba dan kambing (Kementerian Agama 2010). Jumlah hewan kurban domba berdasarkan umur di lima lokasi penelitian disajikan pada Gambar 6. Berdasarkan gambar tersebut, semua domba berumur lebih dari satu tahun

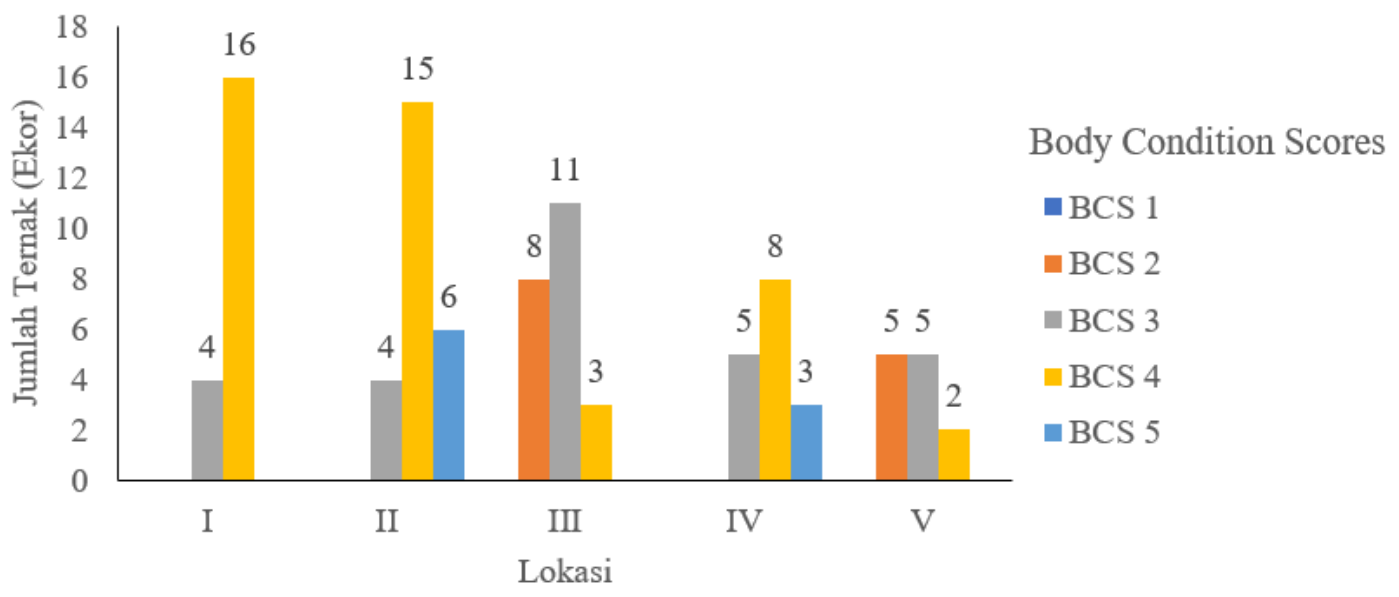

Gambar 4. Jumlah hewan kurban sapi berdasarkan Body Condition Score (BCS) 


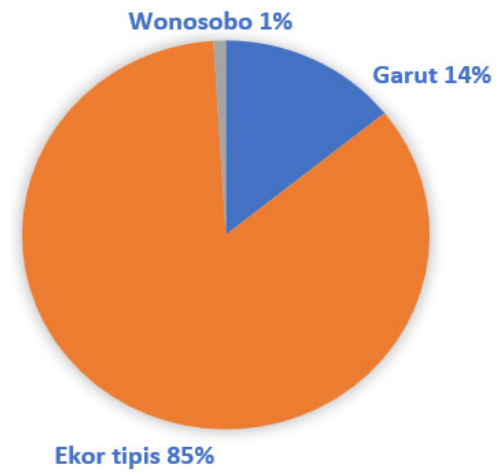

Gambar 5. Persentase domba berdasarkan bangsa

yang berarti sudah memenuhi persyaratan hewan kurban. Menurut Utsaimin (2002) bahwa umur ternak domba sebagai hewan kurban telah genap berusia setahun. Persentase rataan domba tertinggi yang dijadikan hewan kurban yaitu umur domba 2.5-3.0 tahun sebesar 28.9\%, sedangkan persentase rataan domba terendah yang dijadikan hewan kurban yaitu umur domba 1.5-2.0 tahun sebesar 23.3\%. Masyarakat perumahan di lokasi penelitian sudah mengerti mengenai syarat umur domba yang akan dijadikan hewan kurban. Hal ini dibuktikan dengan tidak adannya domba yang berumur kurang dari satu tahun. Pemerintah juga melakukan pengecekan umur dan kesehatan domba yang akan dijadikan hewan kurban di pasar hewan. Pengecekan ini bertujuan agar domba yang akan dijadikan hewan kurban oleh masyarakat memenuhi syarat.

Jumlah hewan kurban domba berdasarkan BCS disajikan pada Gambar 7. Berdasarkan gambar tersebut, persentase rataan BCS yang mendominasi di lokasi penelitian memiliki skor 3 dengan sebesar 46.9\%. Akan tetapi, terdapat satu ekor domba yang mendapat nilai BCS 1 yakni di Lokasi III. Ternak dengan kondisi sakit cenderung memiliki nilai BCS 1 dan hal ini menyebabkan kualitas daging yang dihasilkan rendah (Aji et al. 2017).

\section{Profil Hewan Kurban Kambing}

Kambing merupakan salah satu hewan ternak ruminansia kecil yang banyak dibudidayakan. Persentase kambing berdasarkan bangsa disajikan pada Gambar 8 . Berdasarkan gambar tersebut, persentase bangsa kambing didominasi oleh kambing jawarandu sebesar 46\%. Jumlah kambing yang menjadi hewan kurban di lokasi penelitian sebanyak 15 ekor. Terdapat satu ekor kambing saanen di lokasi penelitian yang berada di Lokasi I. Kambing saanen merupkan kambing yang masih jarang dibudidayakan di Indonesia. Kambing saanen umumnya meupakan kambing tipe perah yang dimaanfaatkan sebagai kambing penghasil susu.

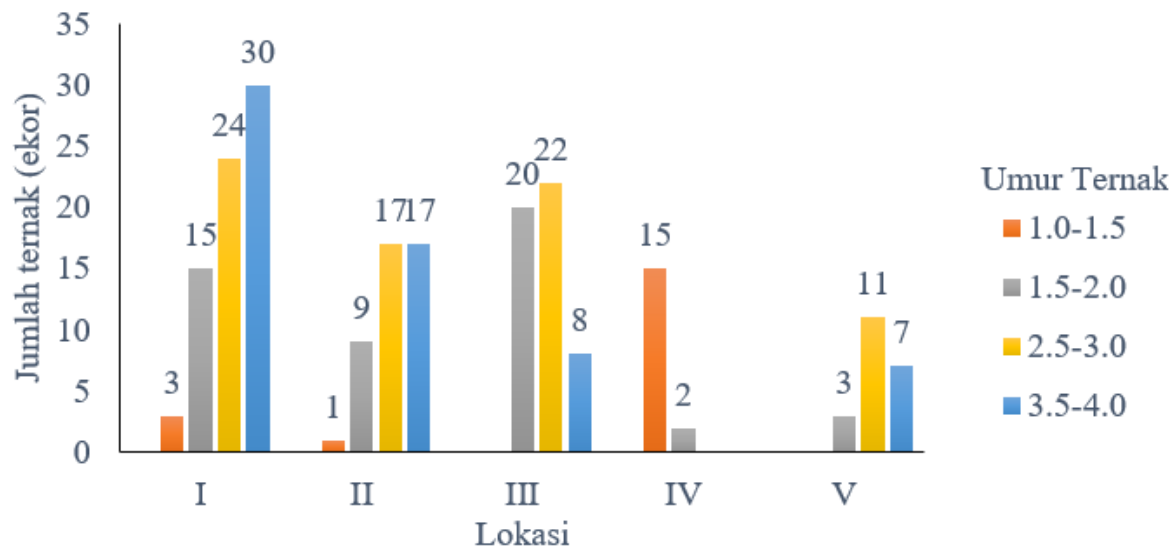

Gambar 6. Jumlah hewan kurban domba berdasarkan umur

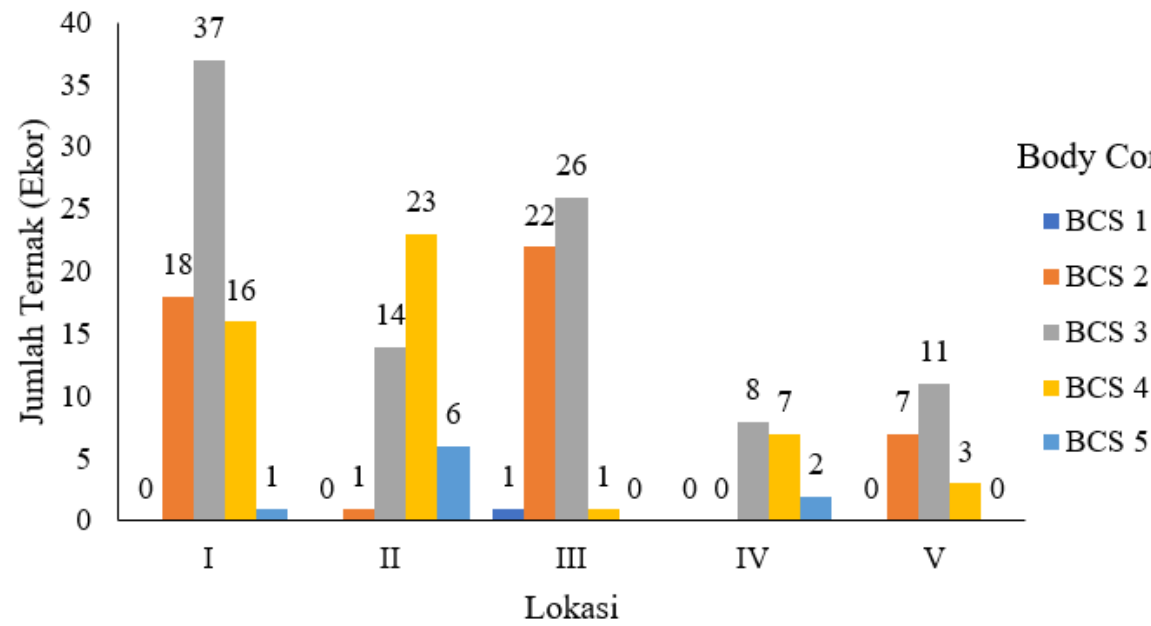

Gambar 7. Jumlah hewan kurban domba berdasarkan Body Condition Score (BCS) 


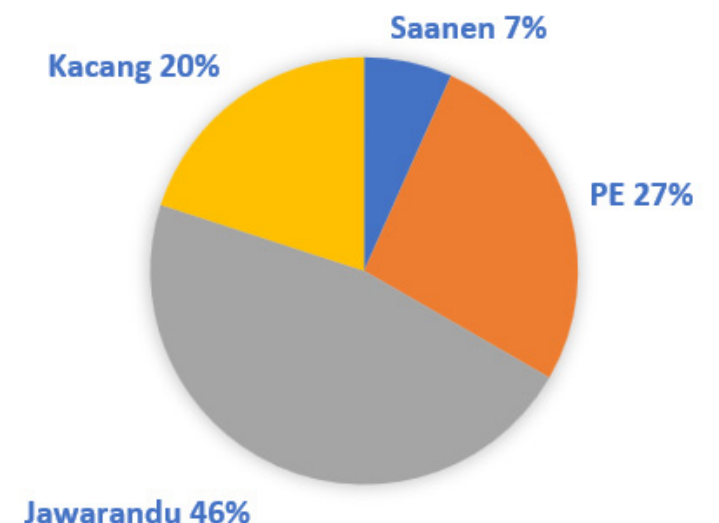

Gambar 8. Persentase kambing berdasarkan bangsa

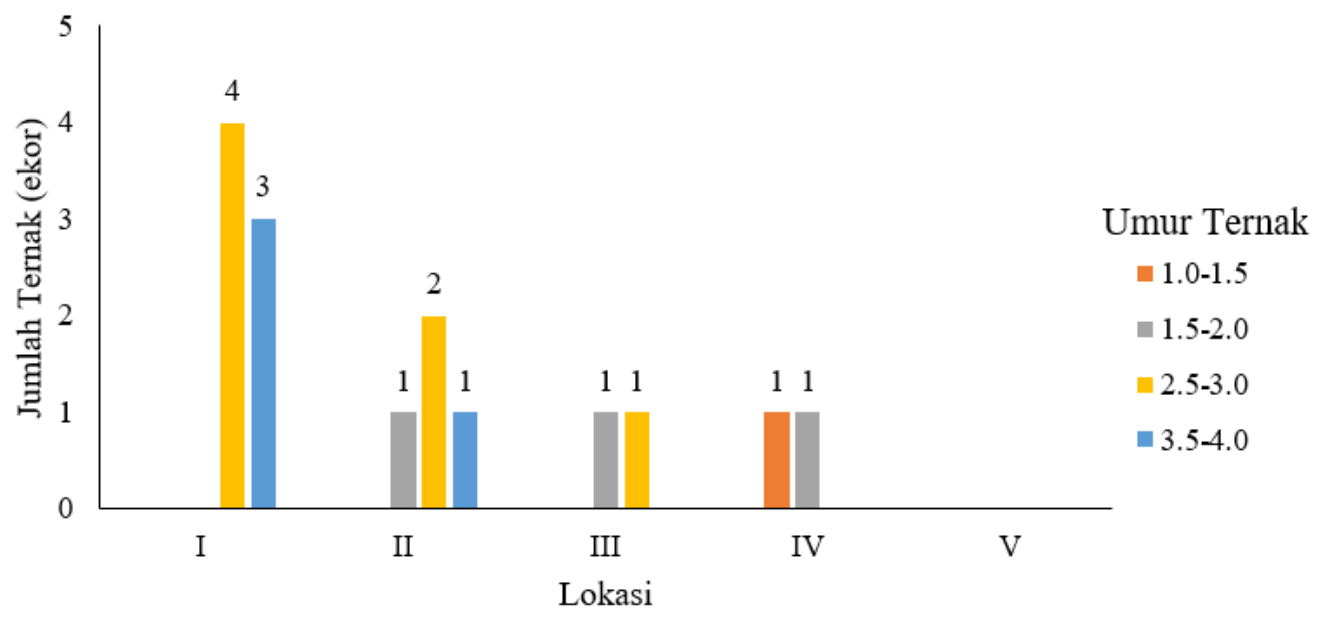

Gambar 9. Jumlah hewan kurban kambing berdasarkan umur

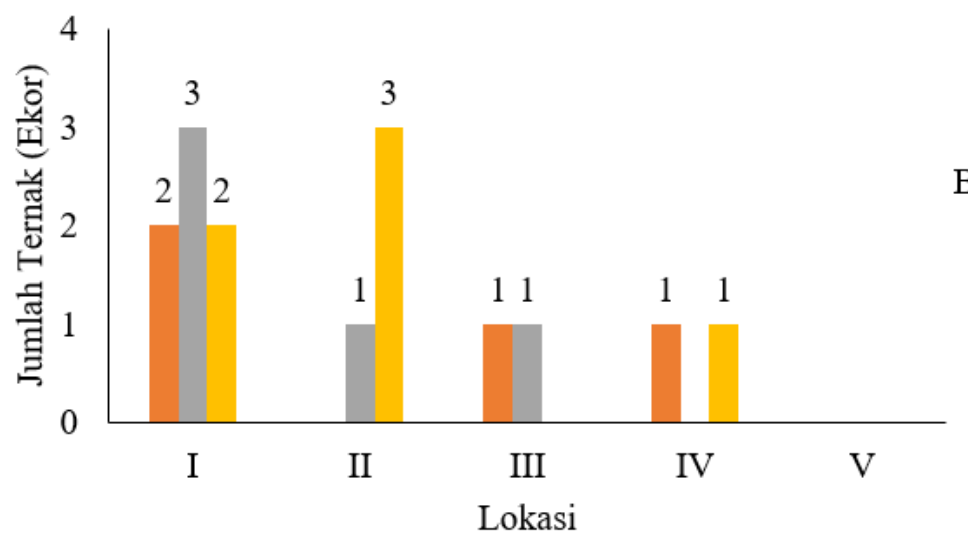

Body Condition Scores

BCS 2

$\because \mathrm{BCS} 3$

BCS 4

Gambar 10. Jumlah hewan kurban kambing berdasarkan Body Condition Score (BCS)

Umur merupakan salah satu indikator kelayakan kambing untuk dijadikan hewan kurban. Hewan kurban harus memenuhi syarat umur yaitu satu tahun untuk domba dan kambing (Kementerian Agama 2010). Jumlah dan persentase domba berdasarkan umur di lima lokasi penelitian disajikan pada Gambar 9. Berdasarkan gambar tersebut, umur kambing di lokasi penelitian didominasi umur 2.5-3.0 tahun sebesar $37.8 \%$. Umur kambing yang menjadi hewan kurban lebih dari satu tahun. Artinya kambing tersebut layak dijadikan sebagai hewan kurban dan memenuhi syarat hewan kurban. Kementrian Agama (2010) dan Utsaimin (2002) mengatakan bahwa hewan kurban harus memenuhi syarat umur yaitu satu tahun untuk kambing.
Jumlah hewan kurban kambing berdasarkan BCS disajikan pada Gambar 10. Berdasarkan gambar tersebut, BCS kambing didominasi oleh skor BCS 4 sebesar 38.4\%. Artinya kambing yang dijadikan hewan kurban di lokasi penelitian dalam keadaan gemuk. Masyarakat perumahan sudah sadar bahwa kurban yang baik adalah berkurban dengan apa yang mereka cintai, dalam hal ini dengan berkurban dengan hewan kurban yang gemuk sebagai tanda syukur kepada Allah SWT. Menurut Dahliati (2019) kesadaran masyarakat dapat dibangkitkan melalui media yaitu pengajian rutin setiap bulan, khutbah Jumat, surat edaran dan adanya pengumuman saat sholat Idul Adha. 


\section{KESIMPULAN}

Simpulan dari penelitian ini yaitu hewan kurban yang dipotong mayoritas sapi bali dengan umur $\geq 4$ tahun sebesar $33.3 \%$, domba ekor tipis umur 2.5-3.0 tahun sebesar 28.9\%, kambing Jawarandu dengan umur 2.5-3.0 tahun sebesar $37.8 \%$. Ternak yang digunakan sebagai hewan kurban sesuai syariah.

\section{DAFTAR PUSTAKA}

Aji, W., D. Dodi, \& U. E. S. Maxs. 2017. Praktik higiene daging dalam penyembelihan hewan qurban di Kota Kupang. JKV. 5(2):99-104.

Amanda, T. D. R., Rizaldi, T. R. Ferasyi, R. Daud, T. F. Karmil, \& Restina. 2017. Analisis data tentang aspek sanitasi penyembelihan sapi kurban di Kota Banda Aceh tahun 2015. JIMVET. 1(2):235-242.

Anisa, E., Y. S. Ondho, \& D. Samsudewa. 2017. Pengaruh Body Condition Score (BCS) berbeda terhadap intensitas birahi sapi induk simmental peranakan ongole (SIMPO). JSPI. 12(2):133-142.

BPS Kota Bogor (Badan Pusat Statistik Kota Bogor). 2019. Kota Bogor Dalam Angka [internet]. [diunduh 2019 September 09]. Tersedia pada https://bogorkota. bps.go.id/.

Dahliati, S. 2019. Faktor faktor yang mempengaruhi kurangnya kesadaran masyarakat dalam berkurban. J. Kesyariah dan Keperdataan. 5(2):258-271.

Handiwirawan, E., \& Subandriyo. 2004. Potesi dan keragaman sumberdya genetic sapi Bali Lokakarya Sapi Potong 2004. Pusat Penelitian dan Pengembangan Peternakan, Bogor.
Kemenag (Kementerian Agama). 2010. Pedoman dan Tata Cara Pemotongan Hewan Secara Halal. Peraturan Kementerian Agama Republik Indonesia, Jakarta.

Khamzah, K2016. Kurban sebagai pendorong produktifitas. Jurnal Pusaka. 4(1):1-10.

Komariah, D. J. Setyono, \& Aslimah. 2015. Karakteristik kuantitatif dan kualitatif kambing dan domba sebagai hewan qurban di Mitra Tani Farm. Buletin Peternakan 39 (2): 84-91.

Noviati, R. 2017. Praktik kurban online dalam perspektif islam tebar hewan kurban THK di Dompet Dhuafa. JSEI. 3(1):343-357.

Palinkas, L. A., S. H. Horwittz, C. A. Green, J. P. Wisdom, N. Duan, \& K. Hoagwood. 2015. Purposeful sampling for qualitative data collection and anlysis in mixed method implementation research. Adm. Policy Ment. Health 42(5):553-544.

Sukandar, A., B. P. Purwanto, \& Anggraeni. 2008. Keragaman Body Condition Score dan Produksi Susu Sapi Perah Friesian-Holstein di Peternakan Rakyat KPSBU Lembang Bandung, Seminar Nasional Teknologi Peternakan dan Veteriner. Fakultas Peternakan IPB, Bogor.

Sosroamidjojo, S. M., \& Soeradji. 1982. Peternakan Umum. CV Yasaguna, Jakarta.

Utsaimin, M. S. A. 2002. Tatacara Qurban Tuntunan Nabi SAW. Media Hidayah, Jogjakarta. 